06,11

\title{
Пироэлектрический и электрокалорический эффекты в твердых растворах $\mathrm{PMN}-\mathrm{PbTiO}_{3}-\mathrm{SrTiO}_{3}$
}

\author{
( Е.П. Смирнова, Г.Ю. Сотникова, Н.В. Зайцева, Г.А. Гаврилов, А.В. Сотников \\ Физико-технический институт им. А.Ф. Иофрфе РАН, \\ Санкт-Петербург, Россия \\ E-mail: Esmirnoffa@gmail.com
}

Поступила в Редакцию 27 мая 2019 г.

В окончательной редакции 27 мая 2019 г.

Принята к публикации 29 мая 2019 г.

\begin{abstract}
Проведены исследования пироэлектрического и электрокалорического эффектов а также диэлектрических свойств в смещающем электрическом поле в твердых растворах магнониобата-титаната свинца-стронция. Обсуждаются особенности температурных и полевых зависимостей пироэлектрического и электрокалорического эффектов.
\end{abstract}

Ключевые слова: релаксоры, пироэлектрический эффект, электрокалорический эффект, твердые растворы.

DOI: 10.21883/FTT.2019.10.48253.493

\section{1. Введение}

Твердые растворы системы $(1-x) \mathrm{PbMg}_{1 / 3} \mathrm{Nb}_{2 / 3} \mathrm{O}_{3}-$ $x \mathrm{PbTiO}_{3}$ (PMN-PT) активно исследуются в качестве эффективных пьезоэлектрических, пироэлектрических, электрострикционных и электрокалорических материалов [1-5]. Фазовая диаграмма этой системы включает в себя как составы - релаксоры $(x<0.3)$, так и составы с концентрацими $x$, соответствующими морфотропной фазовой границе [6]. Сегнетоэлектрики-релаксоры представляют особый интерес для исследования эффектов, под действием внешнего электрического поля, включая пироэлектрический и электрокалорический. Отсутствие доменной структуры в области релаксорного состояния делает такие среды особенно восприимчивыми к внешним воздействиям, таким как электрическое поле, а также температура и давление.

Релаксоры сохраняют симметрию неполярной параэлектрической фазы и не обладают собственным пьезоэлектрическим, а также пироэлектрическим эффектом в области релаксорного состояния. Приложение внешнего электрического поля приводит к появлению полярного направления с преимущественной ориентацией по полю полярных нанообластей (PNR), которые, согласно современным представлениям о сегнетоэлектриках-релаксорах, существуют и могут также индуцироваться полем в области релаксорного состояния.

Пироэлектрический эффект активно исследовался различными методами в релаксорах-твердых растворах $(1-x)$ PMN $-x$ PT $(x<0.3)$ [6-10]. Максимальные величины пироэлектрических коэффициентов составляли $p=(38-50) \cdot 10^{-4} \mathrm{C} \cdot \mathrm{m}^{-2} \cdot \mathrm{K}^{-1}$. Было также установлено, что пироэлектрический коэффициент $p$ в керамических твердых растворах этой системы увеличивается с ростом концентрации титаната свинца $x[6]$.

Электрокалорический эффект (ECE) изучался в керамических твердых растворах $(1-x) \mathrm{PMN}-x$ PT $(x<0.3)$, как с использованием непрямых, так и более достоверных прямых методов, при которых определялось изменение температуры $\delta T$ или изменение энтропии $\delta T$ под действием вонешнего электрического поля [5,11-17]. Полученные величины $\delta T$ варьировались у разных авторов от 0.4 до $1.71^{\circ} \mathrm{C}$ [5,15-17]. Даже у наиболее изученного состава $\mathrm{PMN}-0.1 \mathrm{PT}$ были получена $\delta T=0.45^{\circ} \mathrm{C}[5]$ и $1.25^{\circ} \mathrm{C}$ [17] при измерениях с помощью одного и того же экспериментального метода и близких величинах приложенного электрического поля.

Увеличение концентрации $x \mathrm{PbTiO}_{3}$ в твердых растворах $(1-x)$ PMN $-x$ PT приводит к увеличению электрокалорического отклика (величины $\delta T$ ) с одновременным ростом температур релаксорного состояния (диапазона температур максимумов диэлектрической проницаемости, зависящих от частоты) [18]. В данной работе, для увеличения электрокалорического отклика в твердых растворах $(1-x) \mathrm{PMN}-x$ PT было повышено содержание $\mathrm{PbTiO}_{3}$, а для понижения температуры релаксорного состояния до близкой к комнатной, в состав был добавлен небольшие концентрации $\mathrm{SrTiO}_{3}$. Известно, что $\mathrm{SrTiO}_{3}$ относится к виртуальным сегнетоэлектрикам, в которых сегнетоэлектрическая фаза подавляется квантовыми флуктуациями (нулевыми колебаниями) при $T \rightarrow 0 \mathrm{~K}[19,20]$. Добавление в твердый раствор $\mathrm{SrTiO}_{3}$ позволяет частично компенсировать сдвиг релаксорного состояния в сторону более высоких температур [21]. Целью данного исследования является изучение особенностей пироэлектрического и электрокалорического эффектов в твердых раствоpax $\mathrm{PbMg}_{1 / 3} \mathrm{Nb}_{2 / 3} \mathrm{O}_{3}-\mathrm{PbTiO}_{3}-\mathrm{SrTiO}_{3}$ индуцированных внешним электрическим полем.

\section{2. Эксперимент}

Твердые растворы $0.755 \mathrm{PbMg}_{1 / 3} \mathrm{Nb}_{2 / 3} \mathrm{O}_{3}-0.22 \mathrm{PbTiO}_{3}$ $0.025 \mathrm{SrTiO}_{3} \quad$ (РMPTS-1) и $\quad 0.74 \mathrm{PbMg}_{1 / 3} \mathrm{Nb}_{2 / 3} \mathrm{O}_{3}-$ 

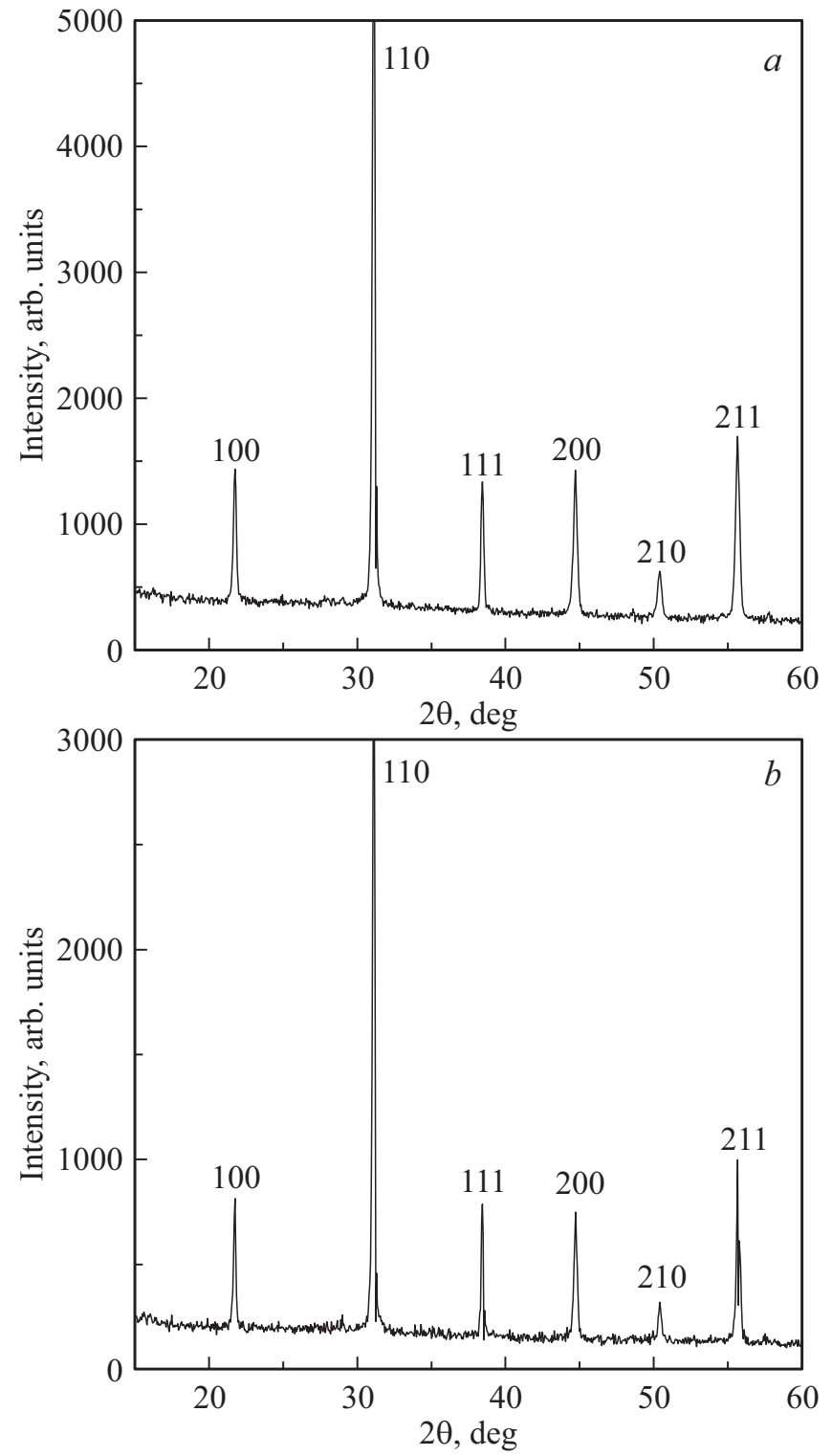

Рис. 1. Рентгенограммы твердых растворов 0.755-0.22 $\mathrm{PbTiO}_{3}-0.025 \mathrm{SrTiO}_{3} \quad$ (PMPTS-1) (a) и $0.74 \mathrm{PbMg}_{1 / 3} \mathrm{Nb}_{2 / 3} \mathrm{O}_{3}-0.2 \mathrm{PbTiO}_{3}-0.06 \mathrm{SrTiO}_{3}$ (PMPTS-2) (b).

$0.2 \mathrm{PbTiO}_{3}-0.06 \mathrm{SrTiO}_{3}$ (PMPTS-2) были изготовлены с использованием прекурсора колумбита $\left(\mathrm{MgNb}_{2} \mathrm{O}_{6}\right)$ a также $\mathrm{PbO}, \mathrm{TiO}_{2}$ и $\mathrm{SrCO}_{3}$ с помощью реакции в твердой фазе. Использование промежуточного соединения - колумбита позволяет получать керамику со структурой перовскита без примеси фазы пирохлора [22]. Керамические образцы PMPTS-1 и PMPTS-2 синтезировались при $1220^{\circ} \mathrm{C}$ в течение часа в атмосфере $\mathrm{PbO}$ для предотвращения потерь свинца и имели плотность 94-96\% от теоретической величины.

Полнота образования твердых растворов контролировалась методом рентгеноструктурного анализа с использованием $\mathrm{Cu}_{\alpha^{-}}$и $\mathrm{Co} K_{\alpha}$-излучения (рис. $\left.1, a, b\right)$. Полученная керамика была однофазной, обладала структурой перовскита без признаков сверхструктуры, что свидетельствует об разупорядоченности структуры. Такая структура является основой существования релаксорного состояния [23].

Зависимость диэлектрической проницаемости от внешнего постоянного электрического поля исследовалась на частоте $1 \mathrm{MHz}$ с использованием стандартной схемы с разделительным конденсатором, высоковольтным источником и измерительным мостом Р5079 при амплитуде измерительного поля $1 \mathrm{~V} / \mathrm{cm}$. Измерения проводились в режиме медленного нагревания со скоростью $1 \mathrm{~K} / \mathrm{min}$ в диапазоне температур от 300 до $400 \mathrm{~K}$. Образцы для диэлектрических измерений представляли собой диски диаметром $9 \mathrm{~mm}$ и толщиной $0.4 \mathrm{~mm} \mathrm{c}$ электродами из возженного серебра.

Пироэлектрический отклик, индуцированный постоянным электрическим полем в синтезированных образцах, изучался с помощью динамического метода модуляции интенсивности лазерного излучения LIMM (Laser Intensity Modulation Method) [24] в диапазоне температур от 265 до $330 \mathrm{~K}$ и во внешних полях до $20 \mathrm{KV} / \mathrm{cm}$. Тепловое воздействие на образец осуществлялось лазерным диодом $(\lambda=0.83 \mu \mathrm{m}$, мощность излучения до $100 \mathrm{~mW}$ ) с модуляцией по гармоническому закону с частотой $0.1 \mathrm{~Hz}$. Изменение и стабилизация температуры образца осуществлялось с помощью элементов Пельтье. Точность поддержания температуры составляла $0.1 \mathrm{~K}$. Измерение пиротока проводилось при нагревании образца.

Исследование ЕСЕ проводились прямым методом с использованием квазиадиабатического калориметра [25] на механически свободных образцах. Измерения $\delta T$ проводились платиновым термометром Pt100 с с разрешением до $5 \cdot 10^{-3}$. Образцы для измерения представляли собой керамические диски диаметром $9 \mathrm{~mm}$ и толщиной $1 \mathrm{~mm}$ с электродами из возженного серебра.

\section{3. Экспериментальные результаты и их обсуждение}

Характерные для релаксоров температурные и полевые зависимости действительной части диэлектрической проницаемости $\varepsilon^{\prime}$ наблюдаются для обоих составов, PMPTS-1 и PMPTS-2. Так, при приложении постоянного смещающего электрического поля вплоть до $10 \mathrm{KV} / \mathrm{cm}$, зависимости $\varepsilon^{\prime}(T)$ размываются с понижением максимальной величины диэлектрической проницаемости $\varepsilon_{m}^{\prime}$ более, чем в 2 раза, и увеличением температуры максимума диэлектрическойпроницаемости $T_{m}=360 \mathrm{~K}$ (PMPTS-1) и $T_{m}=323 \mathrm{~K}$ (PMPTS-2), примерно, на $30 \mathrm{~K}$ (рис. 2, 3).

Температурные и полевые зависимости пироэлектрического коэффициента $p$ для исследуемых твердых растворов приведены на рис. 4, 5, 6. В диапазоне $270-330 \mathrm{~K}$ наблюдаются размытые максимумы $p(T)$, температура которых увеличиваются с ростом приложенного электрического поля. Величина $p$ в максимуме растет при 


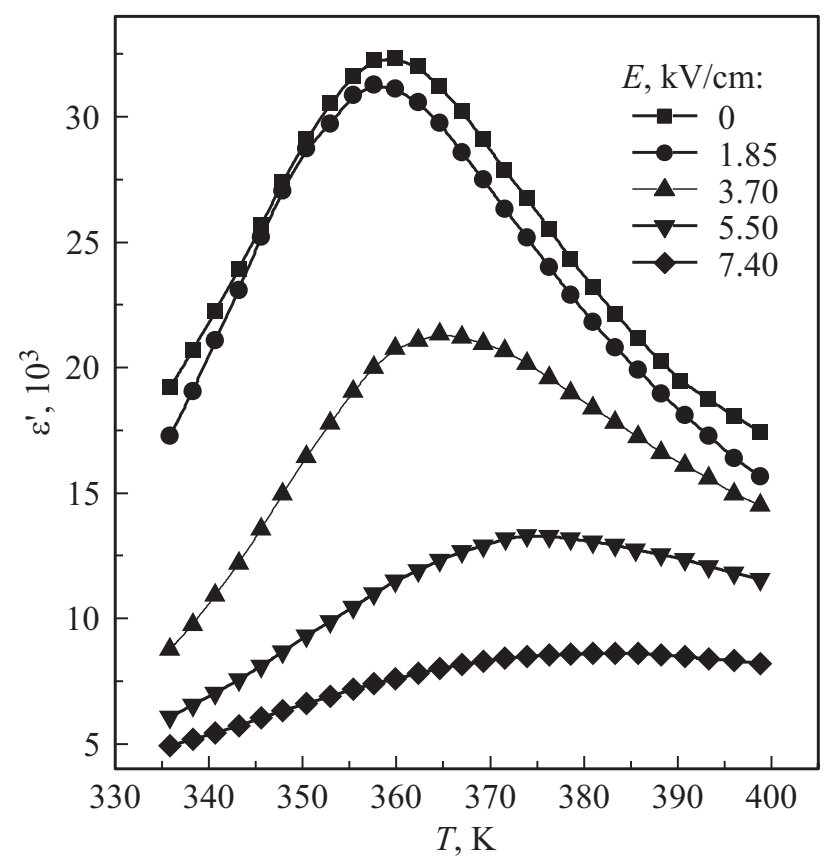

Рис. 2. Температурные зависимости диэлектрической проницаемости $\varepsilon^{\prime}(f=1 \mathrm{MHz})$ для керамики PMPTS-1 при напряженностях электрического поля $E$ от 0 до $7.4 \mathrm{kV} / \mathrm{cm}$.

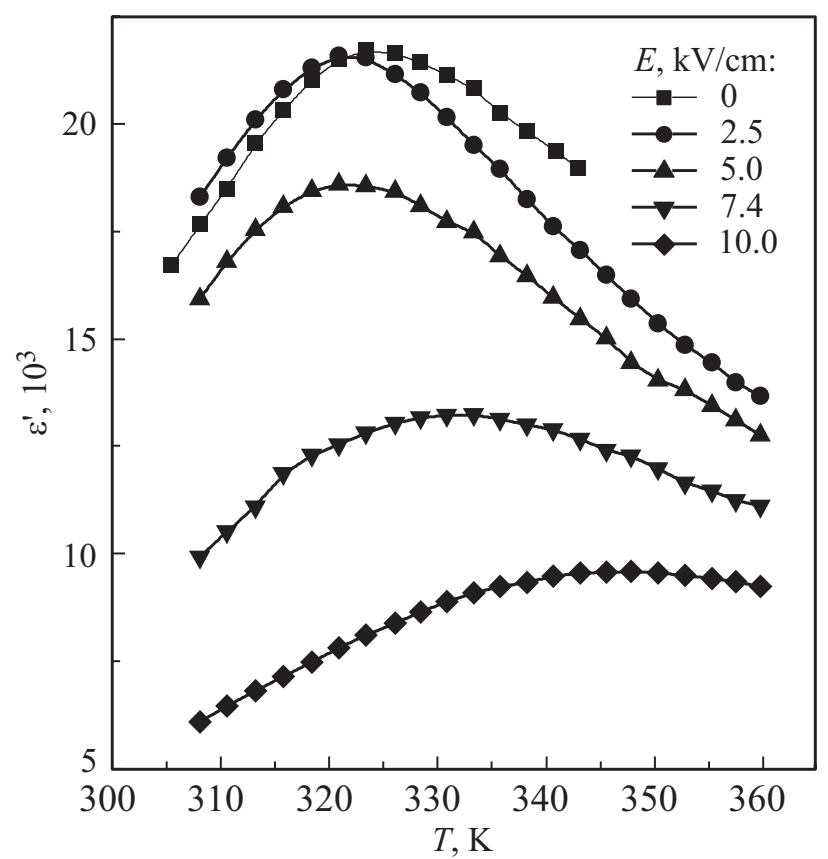

Рис. 3. Температурные зависимости диэлектрической проницаемости $\varepsilon^{\prime}(f=1 \mathrm{MHz})$ для керамики PMPTS-2 при напряженностях электрического поля $E$ от 0 до $10 \mathrm{kV} / \mathrm{cm}$.

увеличении внешнего поля до $10-12 \mathrm{KV} / \mathrm{cm}$, а затем уменьшается (рис. 4,6$)$. Кроме максимумов $p(T)$, твердый раствор PMPTS-1 демонстрирует насыщение пирокоэффициента в температурном диапазоне $315-330 \mathrm{~K}$ при полях $9-16 \mathrm{kV} / \mathrm{cm}$ (рис. 4). Обращают на себя

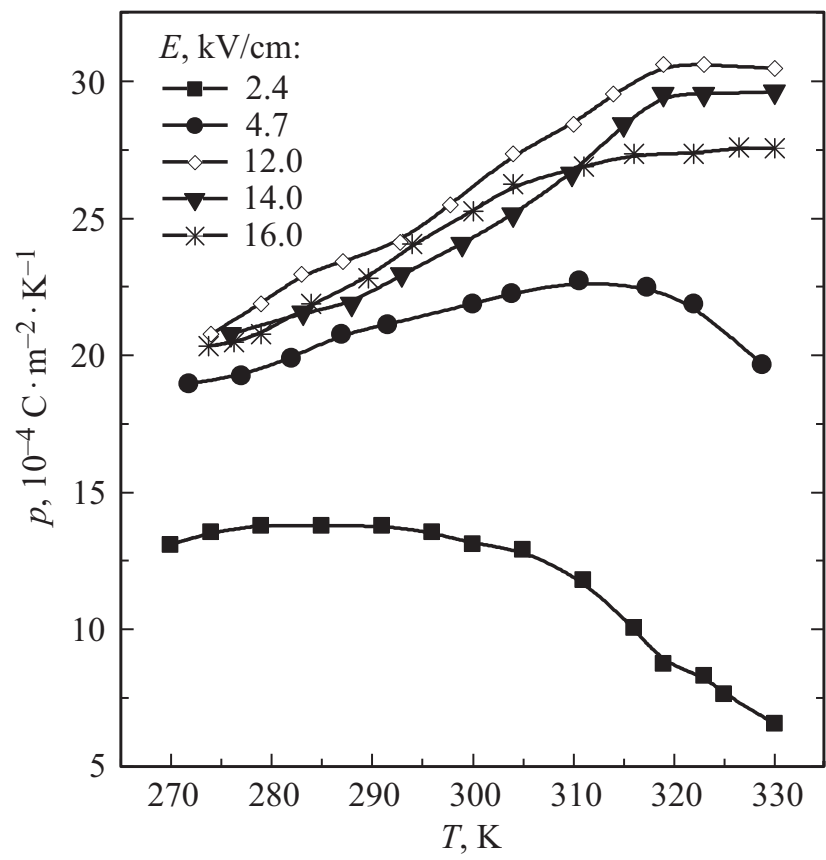

Рис. 4. Зависимость пироэлектрического коэффициента $p$ от температуры для твердого раствора PMPTS-1 при напряженностях электрического поля $E$ от 2.4 до $16 \mathrm{kV} / \mathrm{cm}$.

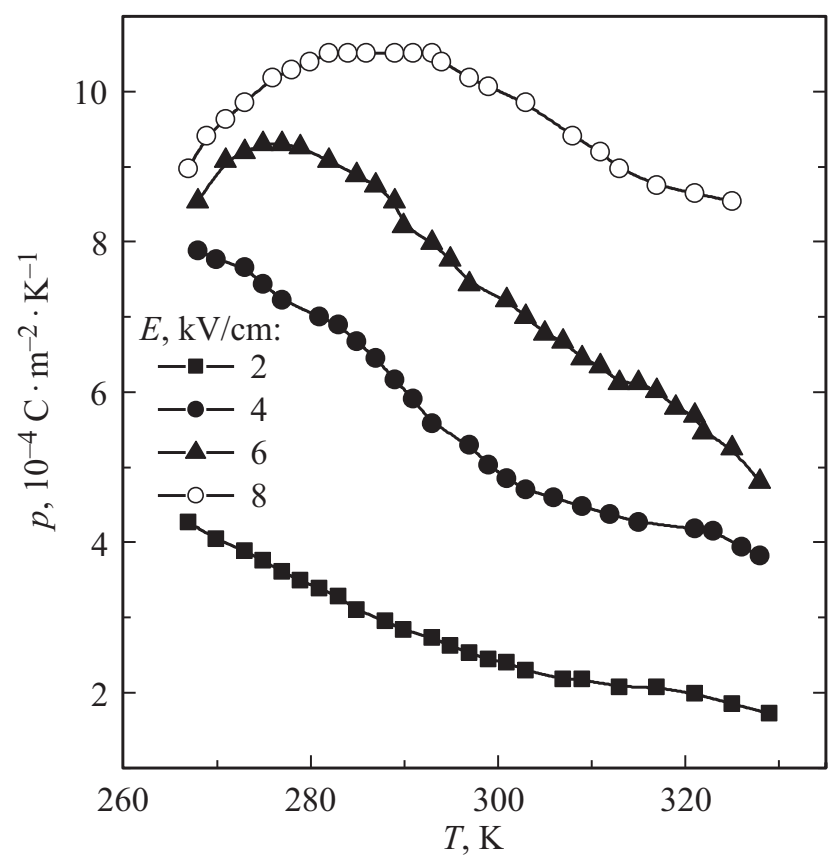

Рис. 5. Зависимость пироэлектрического коэффициента $p$ от температуры для твердого раствора PMPTS-2 при напряженностях электрического поля $E$ от 2 до $8 \mathrm{kV} / \mathrm{cm}$.

внимание зависимости $p(E)$, которые практически не зависят от величины поля при $E=6-14 \mathrm{kV} / \mathrm{cm}$ и температурах $280-325 \mathrm{~K}$ (рис. 6). Существование диапазонов температурной и полевой стабильности пироэлектрического коэффициента является важной особенно- 
стью твердых растворов магнониобата-титаната свинца с добавлением титаната стронция. Для сравнения, на рис. 7 приведены зависимости $p(T)$ для сегнетоэлектрика-релаксора магнониобата-скандониобата свинца [26] и

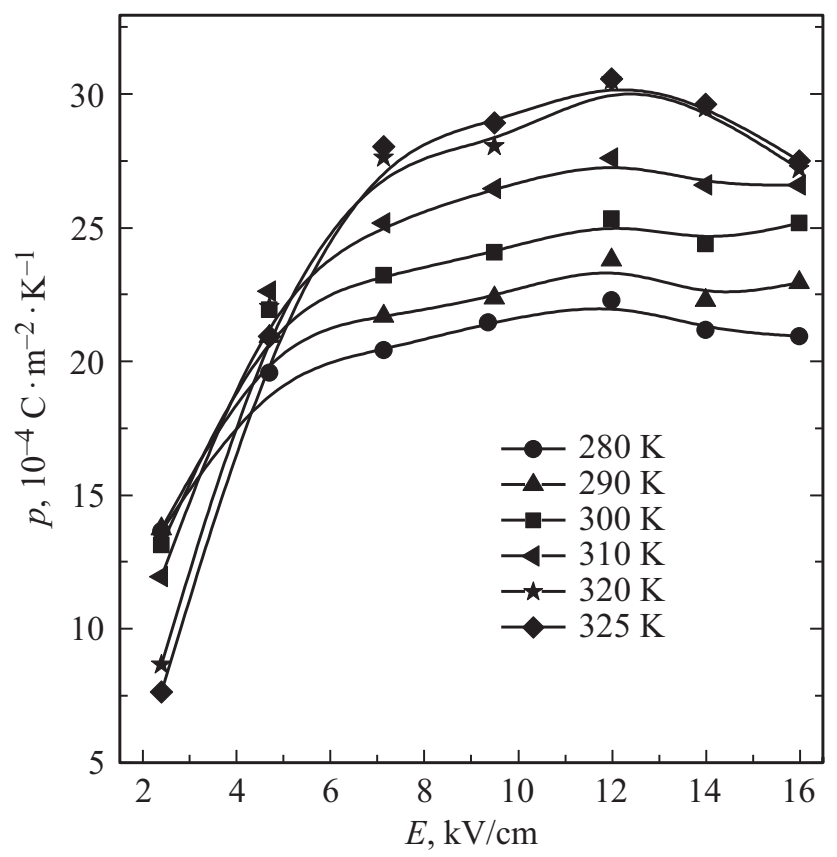

Рис. 6. Зависимость пироэлектрического коэффициента $p$ от напряженности электрического поля $E$ для твердого раствора PMPTS-1 в температурном диапазоне 270-325 K.

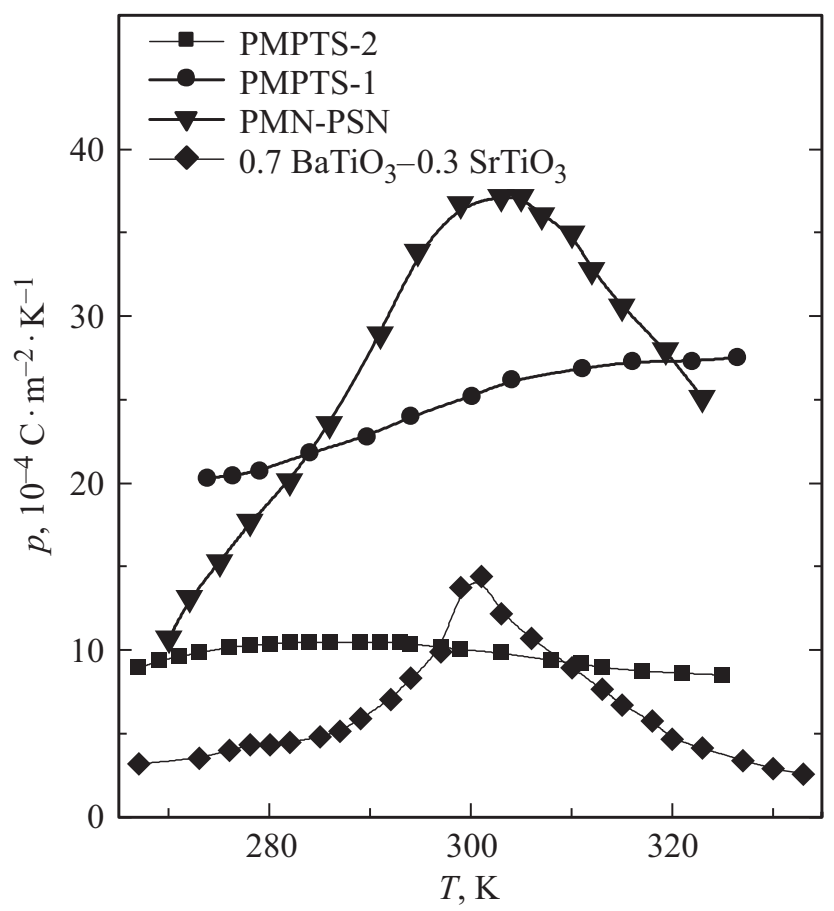

Рис. 7. Сравнение зависимостей $p(T)$ для твердых раствороврелаксоров PMPTS-1, PMPTS-2, магнониобата-скандониобата свинца $\quad 0.55 \mathrm{PbMg}_{1 / 3} \mathrm{Nb}_{2 / 3} \mathrm{O}_{3}-0.45 \mathrm{PbSc}_{1 / 2} \mathrm{Nb}_{1 / 2} \mathrm{O}_{3}$ (PMN-PSN) и сегнетоэлектрика титаната бария-стронция $0.7 \mathrm{BaTiO}_{3}-0.3 \mathrm{SrTiO}_{3}$ с фазовым переходом 1 рода.

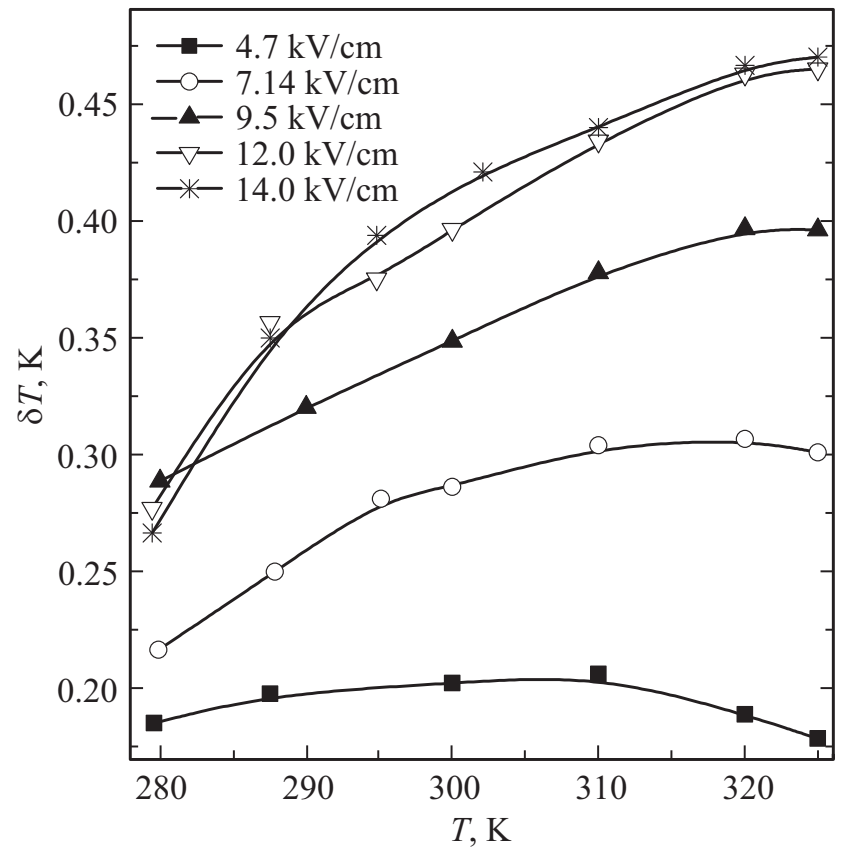

Рис. 8. Зависимость изменения электрокалорического отклика $\delta T$ от температуры для керамики PMPTS-1 при напряженностях электрического поля $E$ от 4.7 до $14 \mathrm{kV} / \mathrm{cm}$.

сегнетоэлектрика с переходом первого рода - титаната бария-стронция [25].

По своей природе пироэлектрический и электрокалорический эффекты неразрывно связаны [27,28]. Электрокалорический эффект определяется как обратимое изменение температуры среды при воздействии внешнего электрического поля в адиабатическом режиме и описывается классическим соотношением [29]:

$$
\delta T=-(T / \rho) \int\left(1 / C_{E}(T)\right)(\partial P(E) / \partial T)_{E} d E,
$$

где $T$ - температура, $E$ - напряженность электрического поля, $P(E, T)$ - поляризация, $C_{E}(T)-$ удельная теплоемкость при постоянной напряженности поля, $\rho$ - плотность. Для релаксоров, демонстрирующих слабую зависимость теплоемкости от температуры и внешнего электрического поля [30], основным параметром, определяющим величину $\delta T$, является пироэлектрический коэффициент $p=\partial P(E) / \partial T$ [28]. Температурные зависимости электрокалорического отклика $\delta T$ для исследованных твердых растворов приведены на рис. 8, 9. Состав PMPTS-1 демонстрирует размытые по температуре максимумы $\delta T$, сдвигающиеся в сторону более высоких температур с увеличением приложенного электрического поля. При самых высоких полях $E=12-14 \mathrm{kV} / \mathrm{cm}$ изменение температуры $\delta T$ достигает величины $0.47 \mathrm{~K}$, которая превышает, например, $\delta T=0.3 \mathrm{~K}$ (при $E=18 \mathrm{kV} / \mathrm{cm})$, обнаруженную для твердого раствора $0.9 \mathrm{PMN}-0.1 \mathrm{PbTiO}_{3}$, не содержащего титаната стронция [14]. Кроме того, полученные зависимости $\delta T(T)$ при высоких величинах электрическорго 


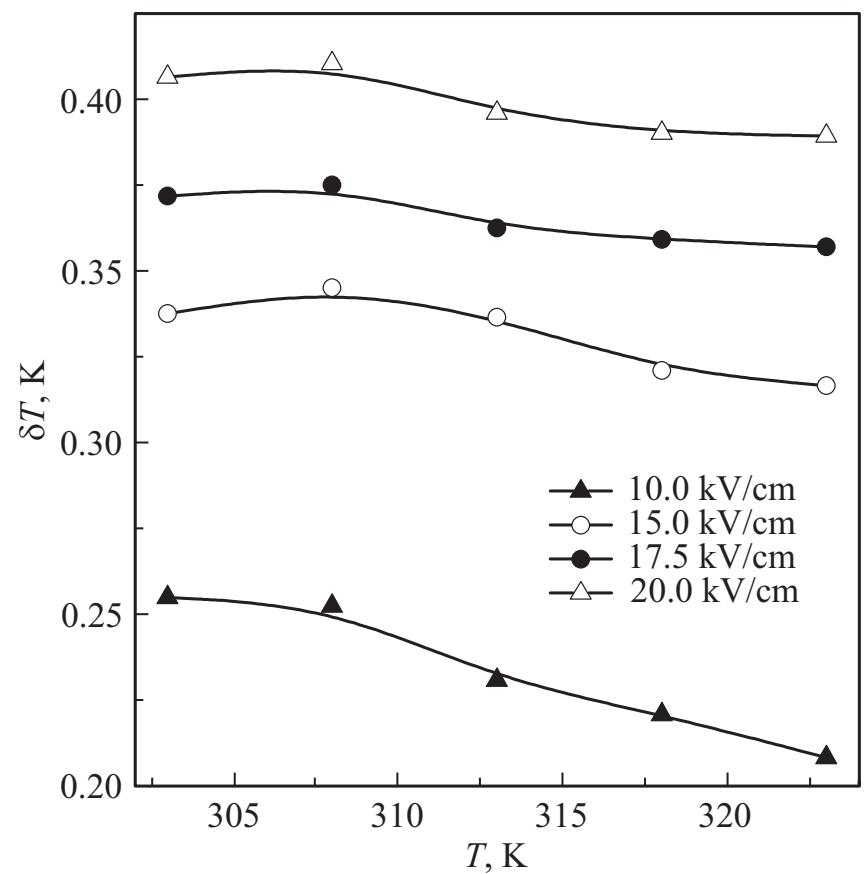

Рис. 9. Температурные зависимости электрокалорического отклика $\delta T$ для керамики PMPTS-2 при напряженностях электрического поля $E$ от 10 до $20 \mathrm{kV} / \mathrm{cm}$.

поля имеют тенденцию к насыщению, что указывают на возможность получения важного для применений термостабильного участка. Несмотря то, что состав PMPTS-2 имеет величины пироэлектрического коэффициента в 2.5 раза меньше, чем состав PMPTS-1, при приложении поля до $20 \mathrm{kV} / \mathrm{cm}$ удается получить $\delta T$ вплоть до $0.41 \mathrm{~K}$ (рис. 9). При этом, понижение $\delta T$ в температурном диапазоне от $300 \mathrm{~K}$ до $325 \mathrm{~K}$ составляет менее $4 \%$.

Таким образом, модификация твердых растворов системы $\mathrm{PbMg}_{1 / 3} \mathrm{Nb}_{2 / 3} \mathrm{O}_{3}-\mathrm{PbTiO}_{3}$ титанатом стронция $\mathrm{SrTiO}_{3}$ приводит к росту электрокалорического отклика $\delta T$ и существенному расширению области его температурной стабильности как для состава $0.755 \mathrm{PbMg}_{1 / 3} \mathrm{Nb}_{2 / 3} \mathrm{O}_{3}-0.22 \mathrm{PbTiO}_{3}-0.025 \mathrm{SrTiO}_{3}$, так и $0.74 \mathrm{PbMg}_{1 / 3} \mathrm{Nb}_{2 / 3} \mathrm{O}_{3}-0.2 \mathrm{PbTiO}_{3}-0.06 \mathrm{SrTiO}_{3}$. Подобная модификация открывает дополнительные возможности для синтеза электрокалорических материалов с улучшенным электрокалорическим откликом.

\section{Финансирование работы}

Работа поддержана Российским Фондом Фундаментальных Исследований, грант 18-02-00394.

\section{Конфликт интересов}

У авторов статьи нет конфликтов интересов.

\section{Список литературы}

[1] B. Noheda. Curr. Opin. Solid State Mater. Sci. 6 , 27 (2002).

[2] К.С. Александров, Б.П. Сорокин, С.И. Бурков, Эффективные пьезоэлектрические кристаллы для акустоэлектроники, пьезотехники и сенсоров. Из-во СО РАН, Новосибирск (2008). T. 2.

[3] S.E. Park, T.R. Shrout. J. Appl. Phys. 82, 1804 (1997).

[4] С.Е. Александров, Г.А. Гаврилов, А.А. Капралов, Е.П. Смирнова, Г.Ю. Сотникова, А.В. Сотников. ЖТФ 74, $72(2004)$.

[5] Y. Hagberg, A. Uusimäki, H. Jantunen. Appl. Phys. Lett. 92, 132909 (2008).

[6] S.W. Choi, R.T.R. Shrout, S.J. Jang, A.S. Bhalla, Ferroelectrics 100, 99 (1989).

[7] D.J. Taylor, D. Damianovich, A.S. Bhalla. Ferroelectrics 118, 143 (1991)

[8] J.R. Giniewicz, A.S. Bhalla, L.E. Cross. Ferroelectrics 118, 157 (1991).

[9] Е.П. Смирнова, С.Е. Александров, К.А. Сотников, А.А. Капралов, А.В. Сотников. ФТТ 45, 1245 (2003).

[10] S.I. Raevskaya, Yu.N. Zakharov, A.G. Lutokhin, A.S. Emelyanov, I.P. Raevski, M.S. Panchelyuga, V.V. Titov, S.A. Prosandeev. Appl. Phys. Lett. 93, 042903 (2008).

[11] B. Rožič, B. Malič, H. Uršič, J. Holc, M. Kozec, Z. Kutnjak, Ferroelectrics 42, 103 (2011).

[12] D. Guyomar, G. Sebald, B. Guiffard, L. Seveyrat, J. Phys. D 39, 4491 (2006).

[13] G. Sebald, S. Pruvost, L. Seveyrat, L. Lebrun, D. Guyomar, B. Guiffard. J. Eur. Ceram. Soc. 27, 4021 (2007).

[14] A. Sternberg, L. Shebanovs, V. Zaulis, K. Kudzins. Ferroelectrics 286, 327 (2003).

[15] D.Q. Xiao, Y.C. Wang, R.L. Zhang, S.Q. Peng, J.G. Zhu, B. Yang. Mater. Chem. Phys. 57, 182. (1998).

[16] L. Shebanovs, K. Borman, W.N. Lawless, A. Kalvane. Ferroelectrics 273, 137 (2002).

[17] L. Shaobo, L. Yanqiu. Mater. Sci. Eng. B 113, 46 (2004).

[18] Y. Bai, D. Wei, L.-J. Qiao. Appl. Phys. Lett. 107, 192904 (2015).

[19] K.A. Müller, H. Burkard. Phys. Rev. B 19, 3593 (1979).

[20] W. Zhong, D. Vanderbilt. Phys. Rev. B 53, 5047 (1996).

[21] Z. Cao, G. Li, J. Zeng, L. Zheng, Q. Yin. J. Phys. D 43, 015405 (2010).

[22] S.L. Swartz, T.R. Shrout. Mater. Res. Bull. 17, 1245 (1982).

[23] N. Setter, L.E. Cross. J. Mater. Sci. 15, 2478 (1980).

[24] S.B. Lang, D.K. Das-Gupta. Ferroelectrics 39, 1249 (1981).

[25] M. Sanlialp, V.V. Shvartsman, R. Faye, M.O. Karabasov, C. Molin, S. Gebhardt, E. Defay, D.C. Lupascu. Rev. Sci. Instr. 89, 034903 (2018).

[26] Е.П. Смирнова, Г.Ю. Сотникова, Н.В. Зайцева, А.А. Капралов, Г.А. Гаврилов, А.В. Сотников. ФТТ 60, 1964 (2018).

[27] Е.П. Смирнова, Г.Ю. Сотникова, Н.В. Зайцева, А.А. Капралов, Г.А. Гаврилов. Письма ЖТФ 44, 49 (2018).

[28] Дж. Най. Физические свойства кристаллов. Мир, М. (1967).

[29] М. Лайнс, А. Гласс. Сегнетоэлектрики и родственные материалы. Мир, М. (1981).

[30] M.V. Gorev, I.N. Flerov, P.H. Sciau, V.S. Bondarev, A. Geddo Lehman. Ferroelectrics 307, 127 (2004).

Редактор Т.Н. Василевская 